\title{
A PROTEIN RELATED TO IMMUNOGLOBULIN LIGHT CHAIN DETECTED \\ IN MOUSE MYELOMA CELLS
}

\author{
George $\mathrm{H}$. Jones
}

Department of Zoology, University of Michigan, Ann Arbor, Michigan 48104

\section{Received January 16,1973}

SUMMARY: A protein (denoted L') which is similar in structure to immunoglobulin light chain has been isolated from the mouse plasma cell tumor, RPC-20. $L^{\prime}$ has a molecular weight which is about 6000 daltons less than light chain. The exact nature of the relationship between $L^{\prime}$ and light chain has not been established.

Several laboratories have recently reported the isolation of the mRNA for immunoglobulin light chain and its translation in cell-free protein synthesizing systems $(1-4)$. In two cases, the products of this cellfree synthesis have been characterized by acrylamide gel electrophoresis $(3,4)$. Milstein et al. (3) have described the properties of a possible precursor of immunoglobulin light chain, synthesized "in vitro" on myeloma or reticulocyte polysomes in response to myeloma mRNA. This putative precursor had a molecular weight somewhat greater than finished light chain, and was not among the products synthesized by myeloma or ascites cell microsomes. Only light chain was detected in the latter systems. Milstein et al. proposed that light chains are synthesized as precursors of somewhat higher molecular weight and are subsequently cleaved to yield the final light chain product. Swan et al. (4) found that mouse myeloma polysomes synthesized several products in response to myeloma mRNA. These included authentic light chain, and proteins with slightly higher and lower molecular weights than light chain.

In view of the fact that Swan et al. and Milstein et al. observed the synthesis of several products in response to myeloma mRNA "in vitro," it seemed desirable to examine and characterize the products synthesized by intact myeloma cells. The data presented below indicated that a protein can be detected in cells of the tumor RPC-20 which is similar in structure to the light chain but has a lower molecular weight.

MATERIALS AND METHODS

The RPC-20 tumor (a $\lambda$ chain producer) was the gift of Dr. Michael Potter, National Institutes of Health, Bethesda, Md. RPC-20 fragments 
were labeled by incubation with ${ }^{14} \mathrm{C}$-glutamine, ${ }^{14} \mathrm{C}$ - or ${ }^{3} \mathrm{H}$-leucine. Incubation mixtures contained: minced tumor fragments, $8 \mathrm{~m} 1$; normal rabbit serum, $1 \mathrm{ml}$; nineteen nonradioactive amino acids, 4 moles each; ${ }^{14} \mathrm{C}$ glutamine or ${ }^{14} \mathrm{C}$-leucine, $20 \mu \mathrm{Ci}$, or ${ }^{3} \mathrm{H}$-leucine, $100 \mu \mathrm{Ci}$; and Hank's solution, $\mathrm{pH} 7.3$, to $20 \mathrm{ml}$. The mixture was incubated with shaking for $2 \mathrm{hr}$ at $37^{\circ}$. The fragments were then removed by centrifugation and the medium saved. Fragments were homogenized in Medium A $(0.05$ $\mathrm{M}$ Tris- $\mathrm{HC} 1,0.025 \mathrm{M} \mathrm{KC1}, 0.005 \mathrm{M} \mathrm{MgCl}_{2}, \mathrm{pH} \mathrm{7.6)}$ containing $0.8 \mathrm{M}$ sucrose, with six strokes of a motor driven Potter homogenizer and four strokes in a Dounce homogenizer. The homogenate was centrifuged for $20 \mathrm{~min}$ at $20,000 \mathrm{~g}$, and the resulting supernatant was again centrifuged for $20 \mathrm{~min}$ at $81,000 \mathrm{~g}$, yielding a pellet of microsomes. The $81,000 \mathrm{~g}$ supernatant was diluted 1:1 with Medium A without sucrose and centrifuged for 75 min at $150,000 \mathrm{~g}$, yielding a pellet of free ribosomes and a supernatant representing the cell sap. Microsomes and free ribosomes were resuspended in Medium A.

L-chain was purified from the incubation media by chromatography

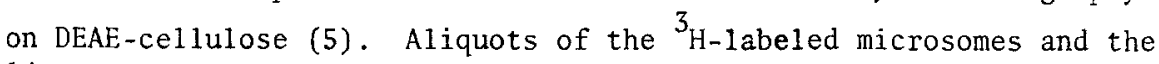
${ }^{14} \mathrm{C}$-labeled light chain were mixed, oxidized with performic acid and digested with trypsin $(200 \mu \mathrm{g})$ for $8 \mathrm{hr}$ at $37^{\circ}$. Tryptic digests were fractionated on a $1 \times 30 \mathrm{~cm}$ column of Dowex $1 \times 2$ (100-200) mesh with a three chamber gradient composed of $2 \%$ pyridine- $1 \%$ collidine, $\mathrm{pH} 8.5$ in the mixing chambers $(2 \times 150 \mathrm{ml})$ and pyridine-acetate, pH 5.0 in the resevoir $(150 \mathrm{ml})$. Aliquots of alternate fractions were examined by liquid scintillation counting.

Aliquots of labeled microsomes, free ribosomes, cell sap or incubation medium were subjected to electrophoresis on $10 \%$ SDS acrylamide gels (6). Gels were cut into $1 \mathrm{~mm}$ slices and counted.

\section{RESULTS AND DISCUSSION}

To examine the products of myeloma protein synthesis, RPC-20 fragmets were labeled by incubation with ${ }^{14} \mathrm{C}$-glutamine. Microsomes, free ribosomes, cell sap and incubation medium (containing secreted light chain) were isolated, and the labeled proteins in each fraction were analyzed by SDS acrylamide gel electrophoresis (6). Fig. 1 depicts the pattern of labeled proteins synthesized on RPC-20 microsomes. Some label sticks to the top of the gel, and there is a broad diffuse band of labeled proteins running from the top to the middle region of 


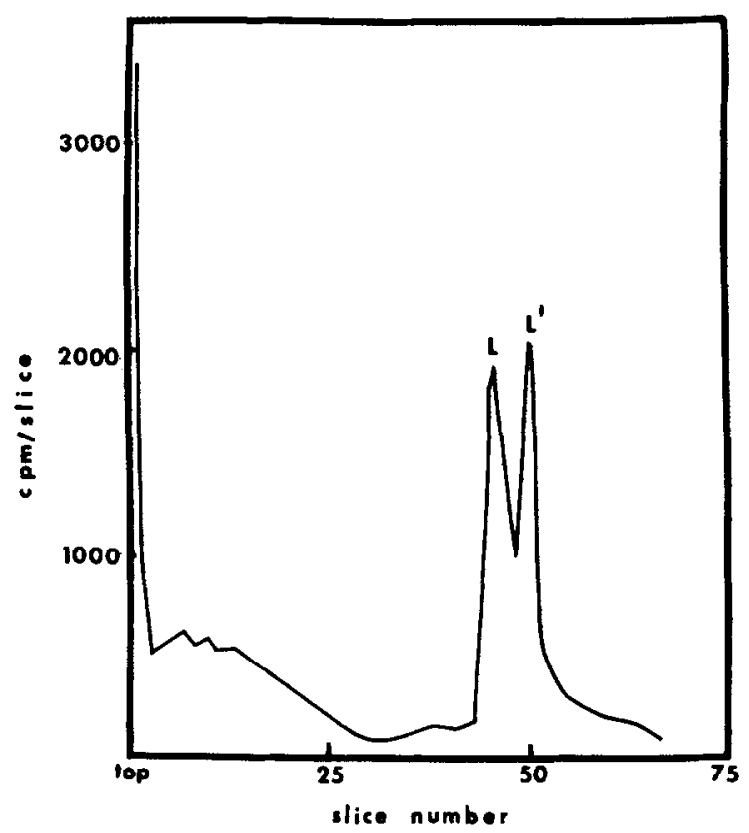

Fig. 1.- SDS gel electrophoresis of nascent proteins present on RPC-20 microsomes. RPC-20 fragments were labeled with ${ }^{14} \mathrm{C}$-glutamine by incubation in a volume of $20 \mathrm{ml}$. The position of the L-chain was determined by coelectrophoreis with purified ${ }^{3} \mathrm{H}$-labeled L-chain.

the gel. The light chain appears near the bottom of the gel and is accompanied by a band of slightly higher mobility. Since SDS gels separate proteins on the basis of their molecular weights (6), the more rapidly migrating band must have a lower molecular weight than the L-chain. This band has been designated L'. Fig. 2 shows that $L^{\prime}$ is also found among the proteins synthesized by free myeloma ribosomes, and among the released proteins present in the cell sap. In contrast, the only product observed in the incubation medium has the electrophoretic mobility of L-chain.

Evidence that $L^{\prime}$ is structurally related to $L$-chain is presented in Fig. 3. Light chain was purified by DEAE-cellulose chromatography (5) and gave a single radioactive peak on gel electrophoresis (Fig. 2). Fig. 3 shows that the pattern of peptides obtained by tryptic digestion of the nascent proteins on RPC-20 microsomes is essentially identical to the pattern obtained for purified light chain. The only difference observed was the ${ }^{3}$ H-peak (peak 6 , arrow) which was absent from the light chain profile. The peptides of peaks 4 and 9 of Fig. 3 were further characterized by paper electrophoresis at $\mathrm{pH} 6.5$. No differences were found in the electrophoretic mobilities of the ${ }^{3} \mathrm{H}$ - and 


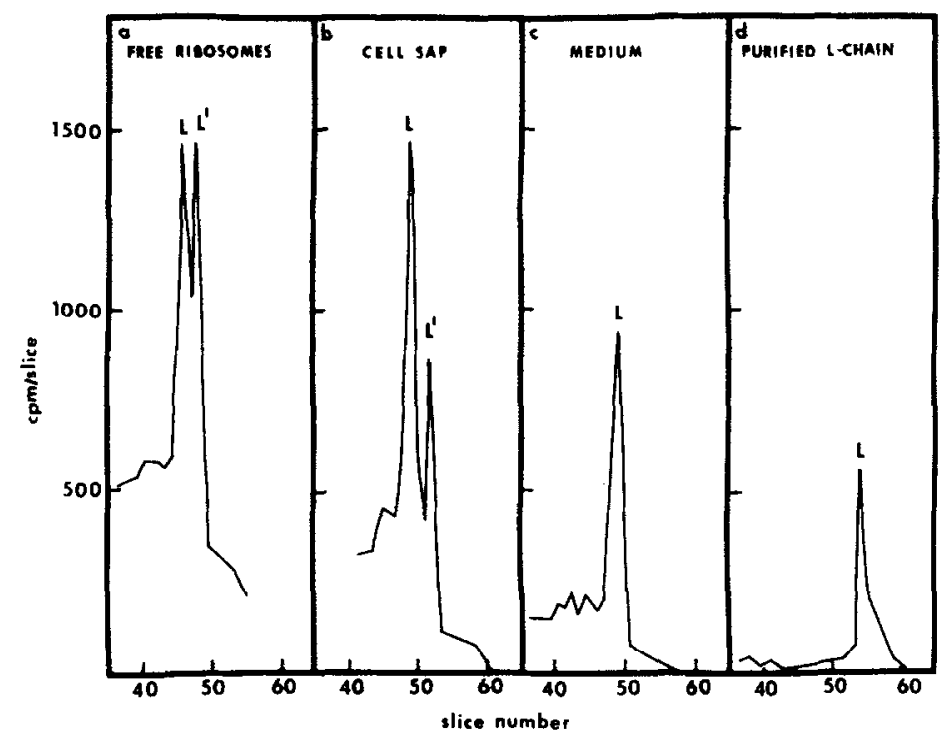

Fig. 2. - SDS gel electrophoresis of the labeled proteins synthesized during a $2 \mathrm{hr}$ incubation of myeloma fragments with radioactive amino acids. For convenience, only the lower portion of each gel is depicted.

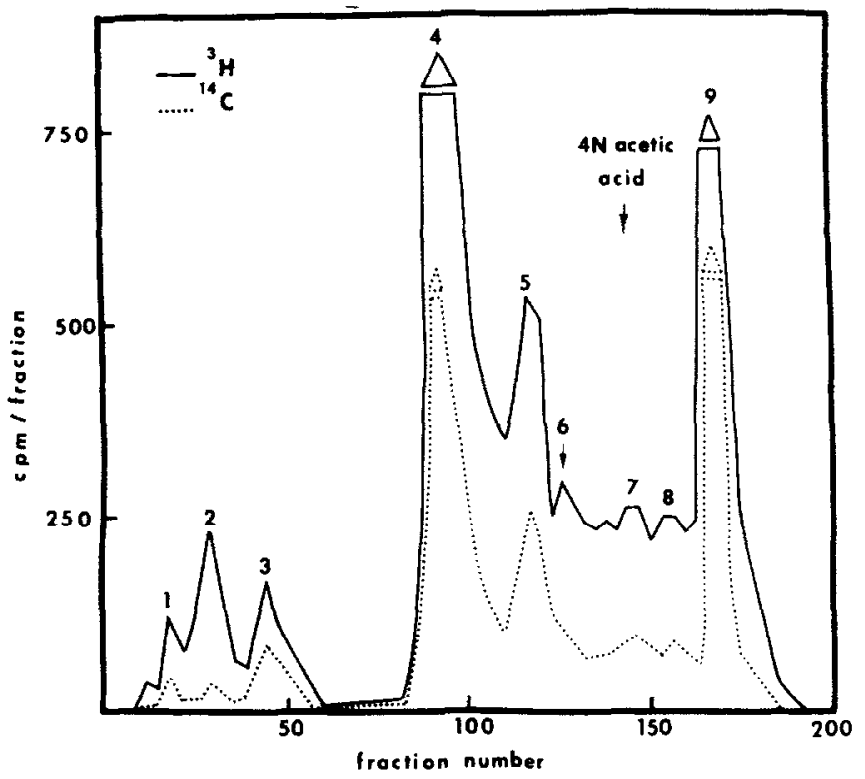

Fig. 3. - Dowex 1 chromatography of tryptic peptides from leucine labeled RPC -20 microsomes and purified light chain.

${ }^{14} \mathrm{C}$-labeled peptides (data not shown). Since $L$ and $L$ are present in about equal amounts on myeloma ribosomes (see below), they should make equal contributions to the peptide pattern of Fig. 3. The close correspondence between the patterns for purified L-chain and nascent 
TABLE I

The data in the table were obtained by summing the cpm in bands $\mathrm{L}$ and $L^{\prime}$ (Figs. 1 and 2 ) and determining the percentage of the total cpm (L plus $\left.L^{\prime}\right)$ represented by $L$ or $L^{\prime}$.

\begin{tabular}{lcr}
\multicolumn{1}{c}{ Fraction } & $\underline{\mathrm{L}}$ & \multicolumn{1}{c}{${ }^{\prime}$} \\
Microsomes & 51.7 & 48.3 \\
Free ribosomes & 57.6 & 42.4 \\
Cell sap & 63.2 & 36.8 \\
Incubation medium & - & 100.0
\end{tabular}

myeloma proteins suggests that $\mathrm{L}^{\prime}$ is very similar in primary structure to the light chain.

Table I gives the relative amounts of $L$ and $L^{\prime}$ found in the three subcellular fractions studied and in the incubation medium. Approximately equal amounts of $L^{2}$ and $L^{\prime}$ are found on microsomes and free ribosomes, whereas the ratio of $L^{\prime}$ to $L^{\prime}$ in the cell sap is about 1.7 to 1 . The fact that no $L^{\prime}$ was found in the incubation medium suggests that the additional amino acids present as a part of the light chain sequence are required for its secretion by the cells. Acrylamide gel data indicate that these additional amino acids represent a molecular weight difference between $L$ and $L^{\prime}$ of about 6000 daltons.

The studies of Swan et al. indicate that a number of proteins are synthesized "in vitro" in response to myeloma mRNA (4). Nevertheless, all the products seemed to be structurally related to light chain. Swan et al. suggested that the proteins of lower molecular weight were produced by incomplete translation of the myeloma mRNA. They also observed a protein with a higher molecular weight than light chain, with electrophoretic properties similar to the putative L-chain precursor of Milstein et al. (3). If this larger protein is indeed the L-chain precursor, it is possible that the lower molecular weight products observed (including $L^{\prime}$ ) are produced by aberrant cleavage of this precursor during its processing to light chain.

\section{ACKNOWLEDGEMENT}

This investigation was supported by research grant 5 RO1 CA12572-02 from the National Cancer Institute, USPHS, and grant IN 40L from the University of Michigan Cancer Research Institute. 


\section{REFERENCES}

1. Stavnezer, J. and Huang, R.C.C, Nature New Biology, 230, 172 (1971).

2. Brownlee, G.G, Harrison, T.M., Mathews, M.B. and Milstein, C., FEBS Lett., 23, 244 (1972).

3. Milstein, C., Brownlee, G.G., Harrison, T.M. and Mathews, M.B., Nature New Biology, 239, 117 (1972).

4. Swan, D., Aviv, H. and Leder, P., Proc. Nat1. Acad. Sci. U.S., 69, 1967 (1972).

5. Potter, M., Methods in Cancer Res., 2, 105 (1967).

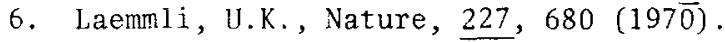

